\title{
Non-conventional therapies for Peyronie's disease: what is the evidence for efficacy?
}

\author{
Ishan Aditya ${ }^{1}$, Jethro C. C. Kwong ${ }^{1}$, Yonah Krakowsky ${ }^{2}$, Ethan D. Grober ${ }^{2}$ \\ ${ }^{1}$ Faculty of Medicine, University of Toronto, Toronto, ON, Canada; ${ }^{2}$ Division of Urology, Department of Surgery, Women's College Hospital \& \\ Mount Sinai Hospital, University of Toronto, Toronto, ON, Canada \\ Contributions: (I) Conception and design: Y Krakowsky, ED Grober; (II) Administrative support: None; (III) Provision of study material or patients: \\ None; (IV) Collection and assembly of data: I Aditya, JCC Kwong; (V) Data analysis and interpretation: I Aditya, JCC Kwong; (VI) Manuscript \\ writing: All authors; (VII) Final approval of manuscript: All authors. \\ Correspondence to: Ethan D. Grober, MD. Mount Sinai Hospital, Sinai Health System, 600 University Avenue, Toronto, ON, M5G 1X5, Canada. \\ Email: Ethan.Grober@sinaihealthsystem.ca.
}

Background: In recent years, there has been a surge in non-conventional therapies for Peyronie's disease (PD). With increasing interest in these novel therapies, we conducted a narrative review to explore the efficacy and safety of these treatments to provide clarity for patients and providers.

Methods: A literature search was conducted to find studies describing non-conventional treatments of PD. These treatments were defined as those within the standard of care, including intralesional therapies and surgical options.

Results: A total of 14 studies were found. Non-conventional therapies included platelet-rich plasma (PRP), hyaluronic acid (HA), combination therapy of PRP and HA, extracorporeal shockwave therapy (ESWT), stem cell therapy (SCT), mycophenolate mofetil (MMF), and H-100. Most studies were limited to animal models and reported modest improvements in angulation and erectile function. Complication rates and cost of each treatment were infrequently reported.

Conclusions: There is limited evidence supporting non-conventional therapies for PD. As such, they are currently not recommended in clinical guidelines.

Keywords: Peyronie's disease (PD); non-conventional therapy; erectile function; penile curvature

Submitted Aug 08, 2019. Accepted for publication Sep 19, 2019.

doi: $10.21037 /$ tau.2019.09.36

View this article at: http://dx.doi.org/10.21037/tau.2019.09.36

\section{Introduction}

In recent years, several novel treatments for Peyronie's disease (PD) have emerged that are not part of current clinical guidelines (1-3). These non-conventional PD treatments include platelet-rich plasma (PRP), hyaluronic acid (HA), combination therapy of PRP and HA, extracorporeal shockwave therapy (ESWT), stem cell therapy (SCT), mycophenolate mofetil (MMF), and H-100. With the rapid expansion and interest in these novel therapies, it is important for both patients and providers to understand the latest evidence supporting their safety and efficacy. The purpose of this narrative review is to analyze the current evidence supporting non-conventional treatments of PD.

\section{Methods}

A comprehensive literature search was conducted. Medline, Embase, Central, CINAHL, and Web of Science were searched to find studies published between January 2000 and January 2019 investigating current non-conventional treatments of PD. The following key terms were used: "Peyronie's Disease" OR "Penile Curvature," AND "Non-conventional treatment" OR "Platelet-rich plasma" OR "Hyaluronic Acid" OR "Extracorporeal Shockwave 
Therapy" OR "Stem Cell Therapy" OR "Mycophenolate Mofetil" OR "H-100". Review articles were excluded. Studies examining conventional treatments for PD were excluded. Our analysis focused on subjective and objective measures of improvement in angulation, erectile function, and pain. Complications and availability of each modality were also compared.

\section{Results}

A total of 14 articles met the inclusion criteria for nonconventional therapies for PD (Table 1). These include PRP,

Table 1 Non-conventional therapies for Peyronie's disease

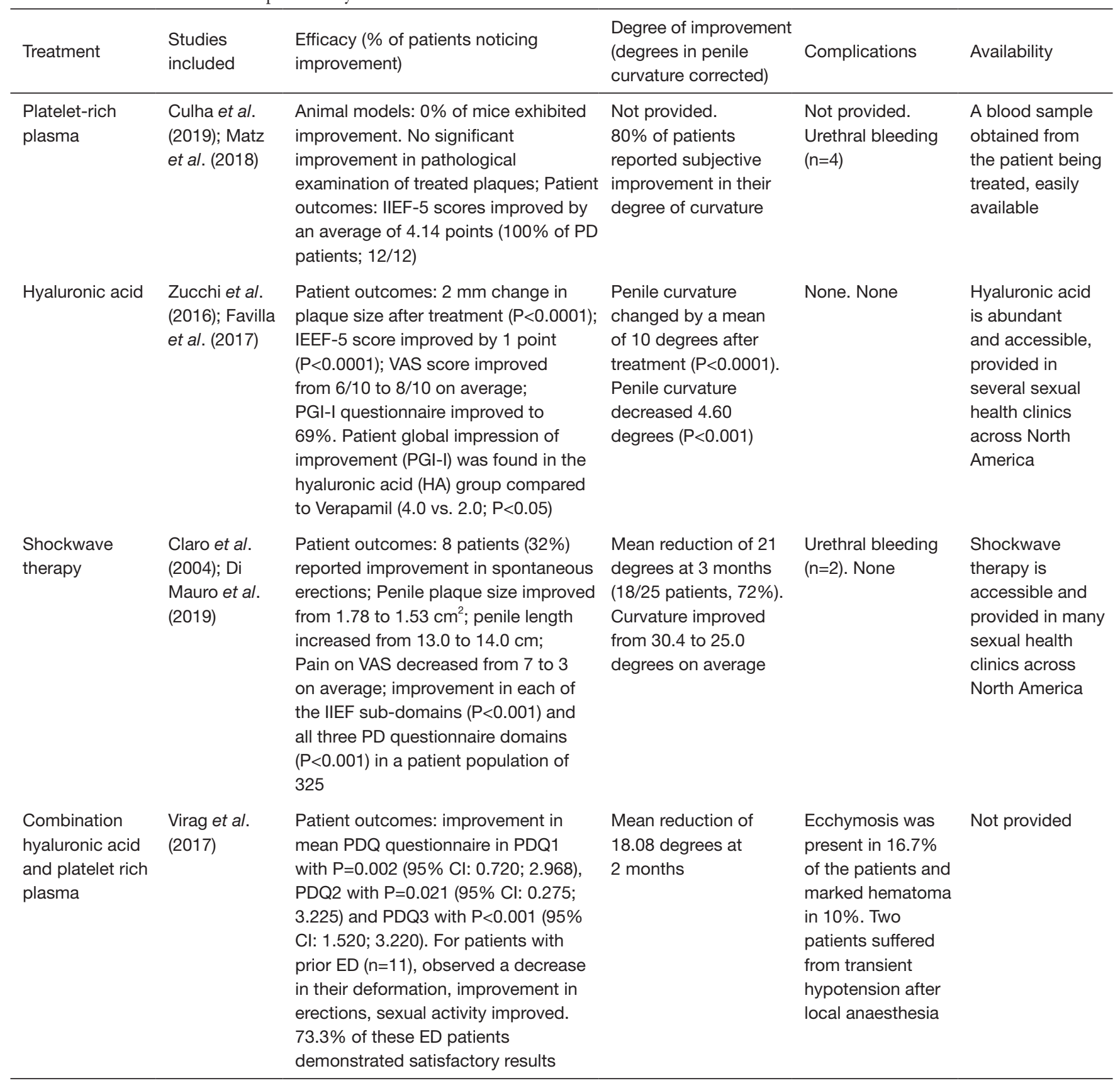

Table 1 (continued) 
Table 1 (continued)

\begin{tabular}{|c|c|c|c|c|c|}
\hline Treatment & $\begin{array}{l}\text { Studies } \\
\text { included }\end{array}$ & $\begin{array}{l}\text { Efficacy (\% of patients noticing } \\
\text { improvement) }\end{array}$ & $\begin{array}{l}\text { Degree of improvement } \\
\text { (degrees in penile } \\
\text { curvature corrected) }\end{array}$ & Complications & Availability \\
\hline $\mathrm{H}-100$ & $\begin{array}{l}\text { Twindell and } \\
\text { Levine (2016) }\end{array}$ & $\begin{array}{l}\text { Patient outcomes: at } 6 \text { months, treated } \\
\text { patients ( } n=11 \text {, with PD }<12 \text { months } \\
\text { duration) reported a } 22.6 \% \text { increase in } \\
\text { mean stretched penile length, } 40.8 \% \\
\text { reduction in curvature, and } 85.7 \% \\
\text { reduction in pain level }\end{array}$ & $\begin{array}{l}\text { Mean reduction of } 20.2 \\
\text { (range, 3-55) degrees } \\
\text { at } 6 \text { months }\end{array}$ & Mild rash $(n=3)$ & $\begin{array}{l}\text { Components } \\
\text { of } \mathrm{H}-100 \text { are } \\
\text { commercially } \\
\text { available }\end{array}$ \\
\hline
\end{tabular}

IIEF, International Index of Erectile Function Questionnaire.

HA, combination therapy of PRP and HA, ESWT, SCT, MMF, and $\mathrm{H}-100$.

\section{Platelet-rich plasma}

PRP is a penile injection formed of various growth factors to facilitate tissue repair and wound healing. These factors include platelet-derived growth factor, transforming growth factor $\beta$ (TGF- $\beta$ ), insulin-like growth factor, epidermal growth factor, and plasma proteins. PRP accelerates wound healing and tissue regeneration in affected regions. While it has been used in other surgical specialties and dental surgery, it is new in the treatment of PD.

In the histopathological examination of TGF- $\beta$ induced Peyronie's plaques in rat models treated with PRP $(n=20)$, Culha et al. reported similar fibrosis scores on $\mathrm{H} \& \mathrm{E}$ staining between the PRP-treated and untreated group (4 untreated vs. $3.4 \pm 0.5$ treated, $\mathrm{P}=0.122$ ) (4). Interestingly, the PRP injection itself induced similar histological features as the Peyronie's plaque created by the TGF- $\beta$ injection. Matz et al. investigated PRP injections in patients with $\mathrm{PD}(\mathrm{n}=17)$, with a mean of 2.1 injections per patient (5). International Index of Erectile Function (IIEF) scores increased by an average of 4.14 points for all PD patients, with $80 \%$ achieving an improvement in erectile function.

However, the study by Matz et al. was non-randomized, retrospective, and lacked a placebo control group (5). The study is also limited by the small sample size. PRP requires injections to the penis, which is not only distressing to the patient but can result in fibrosis of the corpora cavernosa, further worsening the problem. The 2018 study by Culha et al. did not evaluate erectile capacities of the rat by measuring intracavernosal pressure, no staining was made with anti-TGF-B antigen, and a subjective scoring format was used instead of a quantitative method for studying fibrosis (4). 


\section{$H A$}

$\mathrm{HA}$ is an extracellular matrix glycosaminoglycan that can support hydration and turgidity of the amorphous tissue matrix. In PD, HA is thought to oppose factors that promote inflammation and oxidative stress (6). A prospective, multi-center study by Zucchi et al. studied patients who received weekly intraplaque injections with HA ( $n=65)$ (7). At two months post-therapy, plaque size decreased by $2 \mathrm{~mm},(\mathrm{P}<0.0001)$, IIEF-5 scores improved by 1 point $(\mathrm{P}<0.0001)$, average visual analogue scale (VAS) score improved from $6 / 10$ to $8 / 10$, and patient global impression of improvement (PGI-I) scores improved by $69 \%$. Penile curvature improved by an average of $10^{\circ}(7)$. A 2017 double-blinded RCT involving men experiencing the acute phase of PD ( $n=132)$ comparing HA and verapamil demonstrated better PGI-I scores in the HA group (4.0 HA vs. 2.0 verapamil; $\mathrm{P}<0.05$ ) and improvement in mean curvature by $4.60^{\circ}(\mathrm{P}<0.001)(8)$.

The study by Zucchi et al. lacked randomization and a placebo group, in addition to a limited sample size from each center (7). Furthermore, the VAS score was used to measure pain as opposed to standardized erectile questionnaires such as the IIEF. The 2017 study by Favilla is limited by the lack of a control group, short followup (12 weeks), and variability in plaque size measurement amongst the 11 centres (8). Although both studies reported statistically significant improvements in various PD parameters, the absolute changes may not be appreciated clinically.

\section{Combination therapy of PRP and $H A$}

Virag and colleagues investigated the effect of a combination of PRP and HA for the treatment of PD (9). In their study, patients were injected with $8 \mathrm{~mL}$ of PRP and HA directly into the tunica albuginea and repeated 4 times over 2 months $(\mathrm{n}=90)$. They noted improvements across several Peyronie's Disease Questionnaires (PDQ): PDQ1, 0.720-2.968, $\mathrm{P}=0.002$; PDQ2, 0.275-3.225, $\mathrm{P}=0.021$; PDQ3, 1.520-3.220, $\mathrm{P}<0.001$ (9). Patients with prior ED $(n=11)$ were found to have decreased in their deformation, improvement in erections, easier sexual activity, and improvement in their first condition. The mean reduction of angulation was $18.08^{\circ}$ at 2 months, and $73.3 \%$ of these ED patients proved satisfactory results (9). However, this study lacked a control group, making it difficult to gain meaningful insight into this combination therapy compared to the current standard of care.

\section{ESWT}

ESWT was initially explored as an alternative to invasive surgical options. Proposed mechanisms of action included a breakdown of fibrotic tissue by shockwaves and induction of inflammatory response for plaque lysis and removal (10). Claro et al. examined the role of ESWT and high dose vitamin $\mathrm{E}$ compared to vitamin $\mathrm{E}$ alone (11). Of 25 men treated with the dual therapy, $18(72 \%)$ reported a decrease in curvature with a mean reduction of $21^{\circ}$ at 3 months. Similarly, Di Mauro et al. observed in 325 men treated with shockwave therapy that penile plaque size improved from 1.78 to $1.53 \mathrm{~cm}^{2}$, penile length increased from 13.0 to $14.0 \mathrm{~cm}$, pain on VAS decreased from 7 to 3 , as well as improvement in each IIEF sub-domain $(\mathrm{P}<0.001)$ and all three $\mathrm{PD}$ questionnaire domains $(\mathrm{P}<0.001)(12)$.

The study by Claro et al. is limited by small sample size and lacks long-term follow-up (11). The lack of randomization in both the 2004 study by Claro and the 2019 study by Di Mauro make the studies prone to selection bias $(11,12)$. Also, the open-label design without control for both studies may affect clinical outcomes.

\section{$S C T$}

SCT is an emerging modality of treatment for PD. Although the exact mechanism of action is unknown, proposed theories include upregulation of cytokines and trophic factors, reduction in inflammation and oxidative stress, extracellular matrix modulation, and differentiation into target cells to replace damaged tissue (13). Recently, mesenchymal stem cells have gained popularity over embryonic stem cells due to the ethical and logistical challenges associated with the latter. Mesenchymal stem cells are pluripotent and easily accessible, originating from a variety of tissues, including fetal tissue, umbilical cord blood, and adult tissues. Studies have examined the treatment of ED with adipose-derived stem-cells (ADSC). In animal models of ED from vascular or neurological deficits, ADSC has been shown to improve penile hemodynamics (14-16).

Using human ADSC on TGF- $\beta$ treated rat models $(\mathrm{n}=27)$, Castiglione et al. reported decreased expression of disordered collagen type III and elastin, which are found in PD plaques, by $69.9 \%$ and $47.7 \%$, respectively (17). In addition, they found a statistically significant improvement 
in erectile function (intracavernous pressure/mean arterial pressure 0.37 untreated vs. 0.59 treated, $\mathrm{P}=0.03$ ) Gokce and colleagues reported downregulation of tissue inhibitors of metalloproteinases (TIMPs) and increased expression and activity of matrix metalloproteinases (MMPs) with rat ADSC injections with or without interferon $\alpha-2 b$ in TGF- $\beta$ treated rats $(n=24$ and $n=36)(18,19)$. This attenuates the fibrotic response and increases collagen degradation. ADSC has also been studied in tunica albuginea reconstruction in rat models. Ma et al. reported that ADSC-seeded grafts resulted in better preserved cavernosal tissue $(\mathrm{P}<0.001)$ and erectile function $(\mathrm{P}<0.05)$ than graft alone in rats undergoing bilateral incision of tunica albuginea (20).

In human trials, Levy et al. treated 5 patients with a total of 10 Peyronie's plaques with a single injection of placental matrix-derived mesenchymal stem cells (PM-MSC) derived from chorionic placenta (21). Plaque volumes were reduced by $33.3-98.7 \%$ at 6 weeks, $45.8-100 \%$ at 3 months, and close to $100 \%$ at 6 months. Mean reduction in curvature at 6 weeks was $49.7^{\circ}$. Overall, the study noted an improvement in curvature ranging from 30-120 . Peak systolic velocity also improved. There were no statistically significant differences in stretched penile length $(15.2 \mathrm{~cm}$ baseline $v s$. $15.5 \mathrm{~cm}$ at 3 months).

While autologous SCT in PD is exciting due to its pluripotency and minimal risk of rejection, this treatment is still in early experimental phases. At present, most studies are based on rat models with TGF- $\beta$ induced PD (17-21). Given the limitations of animal models, most studies focus on ED, histopathological, and biochemical changes. To date, there is only one study involving humans $(n=5)(20)$. Furthermore, the use of stem cells in regenerative therapy is still controversial due to its oncogenic potential and longterm safety. There are currently no studies comparing oncogenicity between intact and lysed ADSC.

\section{$M M F$}

While primarily used as an immunosuppressant in organ transplantation, mycophenolate mofetil (MMF) has previously been shown to reduce collagen synthesis and fibroblast activity with some success in treating retroperitoneal fibrosis (22). Earlier this year, Antoniassi and colleagues reported the use of MMF on rat models with TGF- $\beta$ induced PD ( $n=20)$ (23). Histochemical and stereological analyses demonstrated that the architecture of elastin and relative proportions of collagen types III and I approached normality following thirty days of MMF (Type
III/Type I ratio: control 0.42 , TGF- $\beta$ 0.82, MMF-7 days $0.65, \mathrm{MMF}-30$ days 0.31 ). This suggests that MMF may be a practical anti-fibrotic agent in PD. However, this study is limited by the small sample size, use of animal models, and the lack of durable long-term data. The authors also note that future studies should determine therapeutic doses for PD.

\section{H-100}

Most therapies described thus far target stable Peyronie's plaques as opposed to acute phase disease. H-100 is a novel topical agent aimed to address this space. It consists of nicardipine as an anti-fibrotic agent like verapamil, superoxide dismutase as an anti-inflammatory by targeting free oxygen radicals, and emu oil as a transdermal carrier agent. Twidwell and Levine studied $\mathrm{H}-100$ in a prospective randomized trial of patients with acute phase PD ( $<12$ months duration, $n=22$ ) (24). Following six months of therapy, improvements were noted in mean stretched flaccid penile length $(22.6 \%$, mean $=2.4 \mathrm{~cm}$, range $=0.7-4.3 \mathrm{~cm}$, $\mathrm{P}=0.0002)$, mean curvature $(40.8 \%$, mean $=20.2$ degrees, range $=3-55$ degrees, $\mathrm{P}=0.001)$, and mean pain level $(85.7 \%$, mean $=3.0$, range $=0-8, P=0.004)$. Similar benefits were observed in the crossover patients from the placebo group. This topical treatment was well tolerated with only a mild rash reported in three of the 22 patients. While this pilot study demonstrates the safety of $\mathrm{H}-100$, larger trials are needed to determine its efficacy and histochemical analyses can be used to examine the connective tissue changes and extent of $\mathrm{H}-100$ penetration into the tunica albuginea (24).

\section{Discussion}

At this time, the evidence supporting non-conventional treatments for PD is limited. Although PRP, HA, combination therapy of PRP and HA, ESWT, SCT, MMF, and $\mathrm{H}-100$ are currently offered in some clinical settings, the quality of evidence is poor due to the methodological limitations highlighted above.

There are currently no recommended oral therapies for the correction of PD according to the Canadian Urological Association (CUA), American Urological Association (AUA), and European Association of Urology (EAU) guidelines (Table 2) (25-27). For pain management during the active form of the disease, nonsteroidal antiinflammatory drugs (NSAIDs) are recommended, along with limiting positions during intercourse to minimize 
Table 2 Current recommendations for non-conventional therapies for Peyronie's disease

\begin{tabular}{|c|c|c|c|}
\hline Treatment & $\begin{array}{l}\text { Canadian Urological Association } \\
\text { (CUA, 2018) }\end{array}$ & $\begin{array}{l}\text { American Urological Association } \\
\text { (AUA, 2015) }\end{array}$ & $\begin{array}{l}\text { European Association of Urology } \\
(E A U, 2017)\end{array}$ \\
\hline Platelet-rich plasma (PRP) & $\begin{array}{l}\text { No Level } 1-4 \text { or Grade A-C } \\
\text { Evidence for treatment of PD. } \\
\text { All current commercial and FDA } \\
\text { therapies are not recommended } \\
\text { as treatments for PD }\end{array}$ & Not available & Not available \\
\hline $\begin{array}{l}\text { Extracorporeal shockwave } \\
\text { therapy (ESWT) }\end{array}$ & $\begin{array}{l}\text { Level } 2 \text { evidence, Grade C } \\
\text { recommendation. Does not } \\
\text { support the use of ESWT for } \\
\text { reduction of penile curvature or } \\
\text { plaque size }\end{array}$ & $\begin{array}{l}\text { Not recommended to use ESWT } \\
\text { for reduction of penile curvature } \\
\text { or plaque size in PD (moderate } \\
\text { recommendation; evidence strength } \\
\text { Grade B). Clinicians may offer ESWT } \\
\text { to improve penile pain (conditional } \\
\text { recommendation; evidence strength } \\
\text { Grade B) }\end{array}$ & $\begin{array}{l}\text { ESWT fails to improve penile } \\
\text { curvature and plaque size but } \\
\text { may be beneficial for penile pain } \\
\text { in PD (Level } 1 \mathrm{C} \text { evidence, Grade } \\
\text { B recommendation) }\end{array}$ \\
\hline $\begin{array}{l}\text { Combination hyaluronic acid } \\
\text { and platelet rich plasma }\end{array}$ & Not available & Not available & Not available \\
\hline Stem cell therapy (SCT) & $\begin{array}{l}\text { Not recommended as a treatment } \\
\text { for PD }\end{array}$ & Not available & Not available \\
\hline Mycophenolate mofetil (MMF) & Not available & Not available & Not available \\
\hline $\mathrm{H}-100$ & Not available & Not available & Not available \\
\hline
\end{tabular}

pain during penetration (25-27). Oral phosphodiesterase-5 (PDE-5) inhibitors are used in patients to improve ED associated with PD (25).

For the correctional treatment of PD, intralesional therapies are recommended. These include the administration of Collagenase Clostridium Histolyticum $\left(\right.$ Xiaflex $\left.^{\circledR}\right)$, interferon $\alpha-2 \beta$, or verapamil $(25-28)$. Collagenase Clostridium Histolyticum is the first FDA, and Health Canada approved therapy for PD (28). The CUA and AUA recommend that clostridial collagenase should be used as first line, followed by verapamil or interferon $\alpha-2 \beta$ as the second line $(25,26)$. In terms of mechanical therapy, penile traction or vacuum pump are recommended as they are shown to correct penile pain and support penile length (25-27). Surgical treatments include penile plication, plaque excision/incision, and grafting, or implantation of a penile prosthesis.

At present, there are several limitations preventing broader applicability of the presented non-conventional PD therapies. Firstly, many of the proposed treatments are still in experimental stages and lack robust randomized control trials in patient populations. Secondly, head-to-head studies comparing these treatments to the standard of care are lacking and would be important for stakeholders when updating clinical guidelines. Thirdly, reporting of statistically significant improvements in PD parameters must also be clinically relevant. Lastly, current studies offer limited discussion on complication rates, cost, and availability, which is essential for patients and providers when making informed decisions about treatment. While the prospect of integrating these treatments into gamut of validated PD therapies is enticing, the current evidence supporting these options is limited and still leaves much to be desired. Until more higher-level evidence is available, patients should be cautioned against using these non-conventional treatments in place of the accepted standard of care.

One must consider why such an explosion of novel therapies exists. From a patient perspective, there is an enormous demand for safer, more effective, and cheaper options. Providers and academics may be motivated by financial and research incentives. As we continue to find new targets for therapies, we may gain added insight into the pathogenesis of PD. Finally, pharmaceutical companies may be interested in entering this market and are facilitated 
by the availability of direct-to-consumer advertising.

\section{Conclusions}

While there are several non-conventional therapies for PD available, the limited and low quality of evidence supporting these alternatives precludes their use as the standard of care. Physicians play a significant role in providing evidencebased recommendations and addressing patient concerns regarding these non-conventional therapies. At this time, larger, randomized prospective studies are needed to understand the therapeutic value better and the risks of these alternatives.

\section{Acknowledgments}

Funding: None.

\section{Footnote}

Provenance and Peer Review: This article was commissioned by the Guest Editors (Larry I. Lipshultz, Alexander W. Pastuszak) for the focused issue "Contemporary Issues and Controversies in Men's Health" published in Translational Andrology and Urology. The article was sent for external peer review organized by the Guest Editors and the editorial office.

Conflicts of Interest: The focused issue "Contemporary Issues and Controversies in Men's Health" was commissioned by the editorial office without any funding or sponsorship. Dr. Grober \& Dr. Krakowsky: Consultants-Paladin Labs. The other authors have no conflicts of interest to declare.

Ethical Statement: The authors are accountable for all aspects of the work in ensuring that questions related to the accuracy or integrity of any part of the work are appropriately investigated and resolved.

Open Access Statement: This is an Open Access article distributed in accordance with the Creative Commons Attribution-NonCommercial-NoDerivs 4.0 International License (CC BY-NC-ND 4.0), which permits the noncommercial replication and distribution of the article with the strict proviso that no changes or edits are made and the original work is properly cited (including links to both the formal publication through the relevant DOI and the license). See: https://creativecommons.org/licenses/by-nc-nd/4.0/.

\section{References}

1. Yafi FA, Pinsky MR, Sangkum P, et al. Therapeutic advances in the treatment of Peyronie's disease. Andrology 2015;3:650-60.

2. Lue TF, Giuliano F, Montorsi F, et al. Summary of the recommendations on sexual dysfunctions in men. J Sex Med 2004;1:6-23.

3. Stuntz M, Perlaky A, des Vignes F, et al. The prevalence of Peyronie's disease in the United States: a population-based study. PLoS One 2016;11:e0150157.

4. Culha MG, Erkan E, Cay T, et al. The effect of plateletrich plasma on Peyronie's disease in rat model. Urol Int 2019;102:218-23.

5. Matz EL, Pearlman AM, Terlecki RP. Safety and feasibility of platelet rich fibrin matrix injections for treatment of common urologic conditions. Investig Clin Urol 2018;59:61-5.

6. Yu CJ, Ko CJ, Hsieh CH, et al. Proteomic analysis of osteoarthritic chondrocyte reveals the hyaluronic acidregulated proteins involved in chondroprotective effect under oxidative stress. J Proteomics 2014;99:40-53.

7. Zucchi A, Costantini E, Cai T, et al. Intralesional injection of hyaluronic acid in patients affected with Peyronie's disease: preliminary results from a prospective, multicenter, pilot study. Sex Med 2016;4:e83-8.

8. Favilla V, Russo GI, Zucchi A, et al. Evaluation of intralesional injection of hyaluronic acid compared with verapamil in Peyronie's disease: preliminary results from a prospective, double-blinded, randomized study. Andrology 2017;5:771-5.

9. Virag R, Sussman H, Lambion S, et al. Evaluation of the benefit of using a combination of autologous platelet richplasma and hyaluronic acid for the treatment of Peyronie's disease. Sex Heal Issu 2017;1:1-8.

10. Husain J, Lynn NN, Jones DK, et al. Extracorporeal shock wave therapy in the management of Peyronie's disease: initial experience. BJU Int 2000;86:466-8.

11. Claro JA, Passerotti CC, Figueiredo Neto AC, et al. An alternative non-invasive treatment for Peyronie's disease. Int Braz J Urol 2004;30:199-204.

12. Di Mauro M, Russo GI, Della Camera PA, et al. Extracorporeal Shock Wave Therapy in Peyronie's Disease: Clinical Efficacy and Safety from a SingleArm Observational Study. World J Mens Health 2019;37:339-46.

13. Chamberlain G, Fox J, Ashton B, et al. Concise review: mesenchymal stem cells: their phenotype, differentiation 
capacity, immunological features, and potential for homing. Stem Cells 2007;25:2739-49.

14. Lin CS, Lin G, Lue TF. Allogeneic and xenogeneic transplantation of adipose-derived stem cells in immunocompetent recipients without immunosuppressants. Stem Cells Dev 2012;21:2770-8.

15. Huang YC, Ning H, Shindel AW, et al. The effect of intracavernous injection of adipose tissue-derived stem cells on hyperlipidemia-associated erectile dysfunction in a rat model. J Sex Med 2010;7:1391-400.

16. Albersen M, Fandel TM, Lin G, et al. Injections of adipose tissue-derived stem cells and stem cell lysate improve recovery of erectile function in a rat model of cavernous nerve injury. J Sex Med 2010;7:3331-40.

17. Castiglione F, Hedlund P, Van der Aa F, et al. Intratunical injection of human adipose tissue-derived stem cells prevents fibrosis and is associated with improved erectile function in a rat model of Peyronie's disease. Eur Urol 2013;63:551-60.

18. Gokce A, Abd Elmageed ZY, Lasker GF, et al. Adipose tissue-derived stem cell therapy for prevention and treatment of erectile dysfunction in a rat model of Peyronie's disease. Andrology 2014;2:244-51.

19. Gokce A, Elmageed ZY, Lasker GF, et al. Intratunical Injection of Genetically Modified Adipose Tissue-Derived Stem Cells with Human Interferon $\alpha-2 b$ for Treatment of Erectile Dysfunction in a Rat Model of Tunica Albugineal Fibrosis. J Sex Med 2015;12:1533-44.

20. Ma L, Yang Y, Sikka SC, et al. Adipose tissue-derived

Cite this article as: Aditya I, Kwong JCC, Krakowsky Y, Grober ED. Non-conventional therapies for Peyronie's disease: what is the evidence for efficacy? Transl Androl Urol 2020;9(Suppl 2):S295-S302. doi: 10.21037/tau.2019.09.36 stem cell-seeded small intestinal submucosa for tunica albuginea grafting and reconstruction. Proc Nat Acad Sci 2012;109:2090-5.

21. Levy JA, Marchand M, Iorio L, et al. Effects of Stem Cell Treatment in Human Patients With Peyronie Disease. J Am Osteopath Assoc 2015;115:e8-13.

22. Scheel PJ, Feeley N, Sozio SM. Combined prednisone and mycophenolate mofetil treatment for retroperitoneal fibrosis: a case series. Ann Intern Med 2011;154:31-6.

23. Antoniassi T, Júnior FN, Spessoto LC, et al. Anti-fibrotic effect of mycophenolate mofetil on Peyronie's disease experimentally induced with TGF- $\beta$. Int J Impot Res 2019. [Epub ahead of print].

24. Twidwell J, Levine L. Topical treatment for acute phase Peyronie's disease utilizing a new gel, H-100: a randomized, prospective, placebo-controlled pilot study. Int J Impot Res 2016;28:41.

25. Bella AJ, Lee JC, Grober ED, et al. 2018 Canadian Urological Association guideline for Peyronie's disease and congenital penile curvature. Can Urol Assoc J 2018;12:E197-209.

26. Nehra A, Alterowitz R, Culkin DJ, et al. Peyronie's disease: AUA guideline. The J Urol 2015;194:745-53.

27. Hatzimouratidis K, Eardley I, Giuliano F, et al. EAU guidelines on penile curvature. Eur Urol 2012;62:543-52.

28. Accessdata.fda.gov. (2018). Drugs@FDA: FDA Approved Drug Products - Xiaflex. [online] Available online: https:// www.accessdata.fda.gov [Accessed 31 May 2019]. 